\title{
LA GESTIÓN DE LAS REDES SOCIALES EN LA COMUNICACIÓN POLÍTICA Y SU INFLUENCIA EN LA PRENSA
}

\author{
MANAGEMENT OF SOCIAL NETWORKS IN POLITICAL COMMUNICATION \\ AND THEIR INFLUENCE IN THE PRESS
}
Francisco Serrano Oceja, Juan Enrique Gonzálvez Valles y Mónica Viñarás Abad
| pserrano@ceu.es | jegonzalvez@ucm.es | monica.vinarasabad@ceu.es | Universidad San Pablo CEU y Universidad Complutense de Madrid

\begin{abstract}
Resumen: El uso de las redes sociales anima a los individuos a acceder a la información política de manera directa, ya sea a través de los perfiles personales de los líderes políticos, sus partidos o los institucionales. Todo ello sin abandonar la información en los propios medios de comunicación, pero ya, con un tiempo limitado. Los políticos, conscientes de esta situación, aprovechan el contacto directo de las redes sociales para buscar la participación entre sus seguidores, lo que puede conducir a la prensa a un momento de crisis. Este trabajo tiene como objetivo analizar el uso que hicieron de Twitter los principales partidos políticos en las Elecciones Generales del 28 de abril 2019, para así averiguar la estrategia de contenido seguida y en qué medida pudo influir en el consumo de prensa. Los resultados obtenidos muestran la manera en que los políticos utilizaron el contenido en redes sociales como estrategia para alcanzar sus objetivos de comunicación, y cómo éste pudo influir en el consumo de prensa. Palabras clave: Prensa; redes sociales; crisis; comunicación política; campaña electoral.
\end{abstract}




\begin{abstract}
The use of social networks encourages individuals to access political information directly, either through the personal profiles of political leaders, their parties or organizations. All this without limiting the information in the media themselves, but already, with a limited time. Politicians, problems of this situation, take advantage of the direct contact of social networks to seek participation among their followers, which can lead to the press in a time of crisis. This work aims to analyze the use made by Twitter of the main political parties in the General Elections of April 28, 2019, in order to find out the content strategy followed and to what extent it could influence press consumption. The results will reach the way politicians will use social media content as the strategy to achieve their communication goals, and how it could influence press consumption. Keywords: Press; Social Networks; Crisis; Political Communication; Electoral Campaign.
\end{abstract}

\title{
1. Introducción
}

¿Por qué consultar en los medios cuando se puede acceder directamente a la fuente de la información política? Casero (2008: 967) explica este cambio social:

Las redes sociales amplían el número y tipo de actores que interactúan y negocian en el campo de la comunicación política. De un escenario marcado, casi exclusivamente, por las relaciones entre periodistas y políticos estamos pasando a un panorama más abierto y descentralizado en el que un mayor número de actores participan de los intercambios que contribuyen a definir la esfera pública gracias a las plataformas digitales. Esto afecta decisivamente a la producción de información política.

Esta sencilla —e incompleta - reflexión puede llevar a muchos ciudadanos a suprimir la prensa de su día a día, sustituyéndola por el acceso directo a la información política. Por su parte, los políticos se esfuerzan cada vez más por generar contenidos de interés adaptados al lenguaje de las redes sociales. Todo ello en un contexto donde el tiempo dedicado a la información es cada vez más limitado y apenas hay lugar para un lectura pausada y reflexiva de los medios. Esta situación conduce a la prensa tradicional a una encrucijada donde su consumo puede verse sustituido por otro tipo de mensajes.

\section{El consumo de la información 2.0}

La digitalización de la información y la convergencia de este fenómeno con el de su distribución en red han traído consigo una nueva era del desarrollo humano de dimensiones históricas (Sotelo, 2012: 220). Estos cambios suponen modificaciones en el modo de comunicación de todos los individuos, tanto a nivel 
personal como corporativo, según indican los autores Cabezuelo, Rey y Tapia (2016: 1269).

La Web 2.0, y especialmente las redes sociales, han cambiado las relaciones entre los individuos y las organizaciones, ya sean relaciones entre empresas y consumidores o entre ciudadanos y organizaciones, instituciones y tercer sector. Los grandes anunciantes, privados o públicos, están apostando por los medios sociales y el éxito de sus estrategias en estos medios radica en la oferta de servicios de valor añadido y promociones exclusivas para los usuarios de sus microsites (Abuín, 2014). En el ámbito político, es fundamental comunicar y explicar las acciones para llegar a la sociedad, como representantes de los ciudadanos que son en la gestión legislativa del Estado. Por su parte, los ciudadanos pueden así conocer y vigilar la gestión de sus políticos, incluso participar de forma inmediata en su toma de decisiones a través de su valoración y opinión en el entorno digital.

Durante décadas, incluso siglos, han sido los medios de comunicación tradicionales (televisión, prensa escrita y radio) los que asumían la responsabilidad de construir esta relación entre el poder político y los ciudadanos: establecer una comunicación que permita el conocimiento y, por lo tanto, el control y cumplimiento de los programas políticos. Hoy en día, las redes sociales han asumido gran parte de este papel, en una relación directa entre el político, el partido o la institución, sin la necesidad del intermediario que suponía el medio de comunicación. Según Chaves (2017: 9):

Las redes se han vuelto el camino rápido y directo para llegar a los ciudadanos y mantener un diálogo permanente con la ciudadanía. El contacto entre los representantes y los representados es una tarea fundamental de la actividad política en una democracia avanzada.

El papel del periodista se ve eliminado con las redes sociales, lo que conlleva la experiencia, interpretación, valoración y conocimientos de estos profesionales; pero, las redes sociales no solo eliminan esta profesionalización de la información, sino que comportan una serie de características en el proceso de comunicación que afectan directamente al proceso y por lo tanto a los efectos del mensaje. La premura con la que se envían los mensajes, su brevedad, la emocionalidad (o posverdad, como prefiere denominarse) de los mismos, la hegemonía de las imágenes, etc. La suma de todo ello, que permite ofrecer una realidad holística, conlleva implicaciones en la relación políticosinstituciones-ciudadanos que afectan directamente a nuestro futuro a través de las elecciones democráticas que conllevan el gobierno de los estados. 
Otro factor que afecta de manera más indirecta, pero no por ello menos importante, a esta nueva situación, es el paradigma creado en torno a la transparencia. En un afán, en algunas situaciones cuestionable por su aplicación extrema y sin un objetivo claro, por ser transparentes, estamos asistiendo a situaciones que en ocasiones pueden resultar excesivas. Vivimos en un mundo donde la transparencia forma parte de todo proceso político y administrativo. Transparencia que también es una exigencia ciudadana y una demanda que marca un cambio de época en el espacio público. Para Cabezuelo, Rey y Tapia (2016: 1263):

Por este motivo, la transparencia se ha convertido en uno de los temas recurrentes en la investigación en las Ciencias de la Información y de la Comunicación. En la medida que se conocen los intereses de los actores participantes en la comunicación pública y que se pueden evaluar los resultados, se mejoran las condiciones del sistema democrático.

Si retomamos la influencia de la Web 2.0, nos tenemos que focalizar en lo que ha supuesto su aparición desde el punto de vista del usuario y cómo se ha empezado a relacionar éste con Internet. Desde el punto de vista tecnológico y de programación no ha supuesto un cambio sustancial, pero ahora sí que se han establecido nuevos marcos relacionales con el sujeto que está al otro lado de la pantalla. Además, hablamos de nuevos formatos de consulta puesto que los dispositivos se han multiplicado y el acceso a la red de redes se ha facilitado en términos generales, aunque siempre existan excepciones vinculadas, casi siempre, a las distintas soluciones políticas existentes.

Internet dejó de ser unidireccional para pasar a dar el protagonismo al usuario, que ahora interacciona de forma efectiva con aquello que le resulta atrayente, irritante, apetecible... Se han establecido, por tanto, nuevos canales para la participación y una multiplataforma portátil desde la que podrá participar en cualquier momento y lugar.

El usuario ahora goza prácticamente del don de la ubicuidad y de la perpetuidad con la construcción de aplicaciones adaptadas a los diferentes dispositivos. La incorporación de la nube como espacio de conservación y archivo garantiza el acceso continuo al usuario, pero no dejamos de lado en este punto los riesgos de seguridad que toda la Web 2.0 ha contraído para sus usuarios.

La Web 1.0 no dejaba de ser un espacio en el que reportar de forma digital lo que anteriormente se hacía de forma impresa. El mensaje no podía ser cuestionado sino por otra Web y el correo electrónico, tan anónimo como fácil de desechar, constituía la principal fuente de interacción. 
Con la llegada de la Web 2.0 la interrelación pasa a ser la piedra angular de todos los espacios de comunicación web. Pero el desarrollo de este nuevo espacio no sólo se queda aquí, sino que además aparecen las redes sociales que, con rapidez, se alzan como las nuevas ágoras digitales. Son nuevos canales de comunicación que dan espacio, forma y, a veces, rostro al usuario, aunque en otras ocasiones el refugio en el anonimato haya sido la opción elegida por parte de estos últimos, con los riesgos inherentes a la misma.

Como ya apuntábamos anteriormente, la incorporación de la nube ha provocado que, cada vez más, se vayan eliminando las aplicaciones de nuestros dispositivos para transformarlas en servicios a través de sus servidores (estén donde estén). El correo electrónico, la gestión de documentos, la obtención de métricas... pasan a ser tan etéreos en su propia definición como palpable en cuanto a su dimensión espacio-temporal.

Como señalan Santiago y Navaridas (2014: 21) «la Web 2.0 ha supuesto un posterior nivel de desarrollo de la web 'tradicional' que ha significado, de hecho, alcanzar un elevado grado de colaboración-cooperación e interacción entre los, cibernautas, que tiende a ser masivo para un gran número de aplicaciones».

Estamos ante lo que se conoce como crossumer, un ciudadano que consume, produce y difunde información, cocreando un discurso con tanta credibilidad - para otros prosumer - como la de los propios políticos. De tal manera, que el periodista se queda relegado como una opción. Ya no es indispensable, hay otras fuentes.

Existen voces en contra de afirmaciones tan contundentes. Para CaseroRipollés (2018: 968), «las plataformas digitales están cambiando la información política, pero no están sustituyendo al periodismo y los medios convencionales». El autor destaca un cambio en la producción de la información, donde las facilidades de producción que poseen las redes sociales provocan que el contenido que circula a través de ellas pueda ser manipulado y/o afectar al proceso de construcción de la agenda pública. Otro rasgo es la distribución, que se multiplica, es un entorno mediático mucho más tupido, saturado y complejo, en el cual conviven los medios de comunicación convencionales con una creciente multiplicidad de plataformas digitales. Cambios en el consumo, como indica Casero-Ripollés (2018: 968):

Esta circunstancia está generando la aparición de nuevas formas de comportamiento entre el público a la hora de consumir la información política. En primer lugar, el acceso a este tipo de contenido es breve e ininterrumpido y se produce en cualquier momento y cualquier lugar. 
Una segunda práctica de consumo informativo que se ha impuesto en el entorno digital es la percepción de que «la información está allí fuera» y hay que salir a buscarla.

En conclusión, no se dejarán de leer periódicos, pero sí descenderá - como ya lo está haciendo - este hábito. Por ello, «los periodistas políticos están obligados a incorporar nuevas técnicas en la producción y distribución de la información, por un lado, y en la gestión de su relación con la audiencia, por otro». Sin duda, el escenario exige una adaptación si no se quiere desaparecer.

\section{Comunicación política en las redes}

Desde el punto de vista político es fundamental comprobar el alcance de la comunicación llevada a cabo. Según Chaves (2017: 22) la variable que puede dar una métrica lo más exacta posible del alcance de los mensajes de los candidatos va a ser la audiencia social.

La audiencia social se define como la suma de los usuarios directos y los usuarios secundarios de estos, la importancia de la audiencia social reside en que es el número potencial de personas a las que nuestros mensajes pueden llegar, serían pues los seguidores de los seguidores directos.

Relacionado con el concepto de audiencia social nos encontramos con otra variable de suma importancia para determinar el alcance de los mensajes. Ésta es las «impresiones», que es una medida de dimensión, la cual representa la suma de todos los seguidores de nivel 1 o primario y de nivel 2 o secundario a los que llega el mensaje por publicación directa más la redifusión del mismo. Las impresiones por tanto se componen de tres elementos, el mensaje original, la respuesta a éste y la redifusión del mensaje, que si lo circunscribe.

De todas las redes sociales, Twitter es una herramienta de gran importancia a la hora de generar conversación e influencia dando a las formaciones políticas la posibilidad de ampliar la difusión de sus mensajes. El 82 por ciento de los políticos encuestados prefiere Twitter para la comunicación política por encima de otras redes sociales (Gutiérrez, 2011). Además, se posiciona como la plataforma perfecta para que los ciudadanos se acerquen a los políticos (Marketing Director, 2016). Los datos reportados apuntan a que ocho de cada diez electores señalan Twitter como una plataforma para la generación de debate político que favorece la participación ciudadana. Una vía de comunicación directa que debe estar basada en la transparencia y la empatía.

Tal es el uso que hacen los políticos y ciudadanos de esta red social que ya hay estudios sobre la evolución de la investigación en relación a este objeto. 
Eva Campos Domínguez (2017) recoge los datos al respecto con muy interesantes conclusiones. En cuanto al tono, en Twitter prima la espontaneidad y la inmediatez, lo que puede fomentar para la autora, un intercambio fluido de la conversación y debate político. Por otro lado, se ha demostrado que la mayoría de los políticos hacen uso escaso de las réplicas en este medio (Shogan, 2010). Crean una cuenta y mantienen cierta presencia, pero resulta mucho más difícil gestionar el debate e interactuar con otros actores. La autora busca las causas y aunque algunas investigaciones han tanteado algunas razones de la baja implicación en el debate por parte de los actores políticos — entre otras, la edad, la ideología, la tasa de penetración de Twitter en el país-, queda todavía espacio para analizar por qué los representantes que lo usan no ahondan en su compromiso con el debate generado.

«Con ello se ha consolidado la idea de que los políticos están más interesados en la difusión de la información y en los retuits que en el debate, de tal forma que permanecen en una burbuja polarizada en su ambiente digital» (Shogan, 2010). La autora concluye afirmando que las redes sociales no resultan tan positivas para la democracia como se anunciaba años atrás.

Rodríguez Fernández (2011: 18) destaca la viralidad e inmediatez de Twitter y define la plataforma como un sistema con «una condición muy especial para facilitar la comunicación bidireccional, por su simplicidad, su facilidad para generar lazos emocionales y su gran poder de movilización». Como afirma Orihuela (2011: 134) «Twitter es la escuela de la escritura breve pero la limitación de 140 espacios no debería ser una excusa para la mala escritura».

El estilo en el que se redacte un tuit marca en gran medida el éxito del mismo, igual que una noticia resulta más o menos atractiva según su titular. La clave está en unir creatividad y una actitud del autor en la que se conjuguen la constancia, la perseverancia, el compromiso y la interacción.

Entre las estrategias que señala este autor para hacer atractivo un tuit, destacan las de entrar en una conversación, comentar un evento, plantear una encuesta, responder a una duda, compartir un artículo interesante, formular una pregunta, publicar contenido propio o exponer lo que se está haciendo en ese momento. Así, se debería escribir un mensaje en Twitter para estas u otras cuestiones semejantes.

En definitiva, desde el lenguaje hasta la velocidad de la información, cada uno de los elementos del proceso de la comunicación se ven afectados en las redes sociales, y Twitter es la preferida para la comunicación política. 


\section{Redes sociales y agenda mediática}

El uso de las redes sociales en política no difiere mucho del uso que se hace por parte de las empresas con sus clientes y consumidores. De hecho, se habla de marketing político, como una estrategia propia de las empresas. La realidad es que son los propios ciudadanos y usuarios los que están creando la agenda mediática a través del uso de las redes.

El trabajo de Túñez, García y Guevara (2011: 53) demuestra cómo el establecimiento de relaciones consolidadas entre los usuarios que participan en los contextos sociales virtuales, y el ejercicio de prácticas vinculadas con el marketing viral, pueden alterar el proceso tradicional de producción informativa.

La agenda mediática se había construido con la participación del medio y sus fuentes, pero, en la actualidad, la participación activa de muchos de estos usuarios en la red repercute en la creación de contenidos que ellos mismos elaboran y difunden mediante técnicas virales. Estos contenidos no son información periodística en la mayoría de los casos, pero cuando alcanzan repercusión acaban siendo noticia y accediendo al temario de los medios tradicionales y digitales, de manera que son los propios usuarios los que promueven los contenidos que los medios seleccionan para elaborar el temario que dirigen a los ciudadanos.

Como indican los autores, los ciudadanos no son periodistas, pero crean contenido y seleccionan temas, de tal forma que muchas veces son ellos los que determinan qué es y qué no es noticia. A través del entorno con el que mantienen relaciones discuten y analizan los temas que les inspiran interés, y con las valoraciones de unos y otros van creando y elaborando su propia información (Túñez, García y Guevara (2011: 55):

En los escenarios virtuales todo este proceso se simplifica de manera notoria, tanto en el contraste de fuentes como en las vías de publicación y difusión pública de los hechos relevantes. En los foros, en los blogs, en las redes sociales o en las webs los ciudadanos hacen público lo que desde lo privado les merece interés. Lo comparten con sus contactos, lo discuten y analizan con textos e imágenes con todos los miembros de su comunidad virtual o, lo que es igual, con todos los miembros con los que mantienen relaciones.

Los medios de comunicación tradicionales — prensa, radio y televisión-, y también los nuevos medios digitales — periodismo digital— son conscientes. 
Los medios no pueden obviar los intereses de la ciudadanía y, en buena lógica, según los autores, lo que los usuarios valoran en los entornos sociales virtuales acaba por convertirse en noticia y accede, de este modo, al temario, de tal forma que los hechos que alcanzan notoriedad informativa en la red social y comunitaria suelen conseguirla también en los medios de comunicación.

Mónica López Abellán (2012: 69) habla incluso de branding político en una situación totalmente novedosa. En este sentido, son numerosos los autores que empiezan a hablar de la exigencia de una democracia cada vez más participativa, donde la ciudadanía no se limita sólo a votar a un candidato cada cuatro años, y cada vez son más habituales en los estudios de ciencia política y comunicación política términos acuñados por diversos autores que intentan definir las transformaciones de las nuevas democracias contemporáneas al compás del uso de Internet y las nuevas tecnologías (Dader y Campos, 2012): teledemocracia, democracia electrónica, política virtual, netdemocracia, democracia digital o ciberdemocracia. Así, como explican Alonso y Adell (2011: 83), «el término ciberdemocracia abarca todas las formas de comunicación y acción basadas en las nuevas tecnologías digitales destinadas a la acción política para conseguir la participación de los ciudadanos en los procesos políticos» Frente a esta nueva capacidad adquirida por los individuos el poder político tiene dos opciones: puede aprovecharla para regenerar la democracia con más participación ciudadana o puede caer en la tentación de «colonizar estos mundos vitales para su propio interés» (Matud, 2009). Como apunta López Abellán (2012), en los últimos años podemos hablar, en este sentido, de en tanto en cuanto asemejan el proceso de generación de valor aplicado a un producto al de un candidato político para diferenciarse del resto a través de la imagen de marca, de branding político. En esta estrategia de branding, Twitter cobra un papel relevante, Twitter es de entre todas las redes la que actualmente más relevancia ha adquirido entre la clase política.

Incluso uno de los últimos campos en los que se están centrando las más recientes investigaciones sobre Twitter comprenden el uso de esta red como herramienta demoscópica para revelar el sentimiento político de los usuarios a través de la minería de opinión en los mensajes o tuits. El trabajo de López Abellán a recogía en las elecciones generales de 2011 el uso estratégico que hacían los políticos.

En definitiva, la comunicación política podemos estructurarla en torno a dos ejes básicos: transversalidad y receptividad, donde se puede concluir que nos encontramos ante una situación donde la prensa no tiene más alternativa que reinventarse para seguir haciendo su trabajo: informar (Caldevilla, 2009). 


\section{Metodología}

Para comenzar el recorrido del desarrollo metodológico de nuestra investigación tenemos que hacer obligada referencia al análisis en redes sociales de forma general para después adentrarnos en cómo afecta a la crisis de la denominada prensa tradicional, esto es, la difusión de las noticias entre los diferentes públicos de interés. Pérez Tornero (2015) marca el origen de la sociedad digital en el pulso por el control de las potencialidades de la comunicación y la promesa de democratización gracias al avance de la tecnología. Hemos pasado, por tanto, de un modelo donde los medios destacaban por una cuasi total unidireccionalidad y un control omnímodo de las cuatro variables del marketing mix, a un sistema donde el acceso multiplataforma, multisoporte y multicanal de los contenidos llevan aparejado un método matemático de medición que se retroalimenta desde el propio contenido y hacia y por el usuario que accede a la opinión publicada.

La crisis de la prensa se ve favorecida por un «ecosistema dominado por pocas plataformas que tienen una influencia tremenda sobre lo que vemos y sabemos» (Bell y Owen, 2017: 76). Desde esta perspectiva, las redes sociales se han erigido una fuente constante de comunicación en un entorno digital cambiante y aquí es donde Twitter se crea con una función clara: una red de microblogging que en 2006 arranca para que el usuario pudiera expandir su universo interior y exterior como un torrente que fluye pero que desaparece en un periodo de tiempo de corta duración. Como afirman Cabezuelo y González (2014: 28):

Las redes sociales se han convertido hoy en un ágora virtual, en un espacio público inmaterial al que cualquier persona tiene acceso y en el que también se desarrollan actividades económicas, políticas y culturales como en la antigua ágora griega. De hecho, las redes sociales se usan como termómetro para medir la temperatura de la opinión pública.

Su labor primigenia estribaba en la muestra del minuto a minuto de cada usuario y de las acciones que realizaba. Sin embargo, el sentido de pertenencia provocó que rápidamente derivara hacia la posibilidad de comentar lo que el usuario observaba a su alrededor. Como la propia red calificó en su caja de introducción de texto, se pasó del «¿Qué estás haciendo?» al «¿Qué está pasando?».

De forma adicional, Twitter incorporó la capacidad de poder medir los resultados de las comunicaciones propias a través de su Analytics. Aunque esta función se incorporó tras varios años de petición por parte de los usuarios, su eficacia resulta patente desde el punto de vista cuantitativo, lo que nos 
puede derivar posteriormente hacia una clara y cristalina opción de establecer parámetros cualitativos. Como veremos en nuestra investigación, incorporaremos primero la medición de resultados pertinentes al objeto de estudio para después añadir los comentarios y contexto necesarios que nos permitan cristalizar unas diáfanas conclusiones.

No nos enfrentamos a una cantidad de datos ingente que produce una masa informe difícil de analizar, sino que encaramos un entorno acotado en el tramo correspondiente en el periodo de la campaña electoral a las elecciones generales en España en 2019. Este tramo queda claramente definido por las leyes y, en nuestro caso, empieza el 12 de abril y finaliza el 26 del mismo mes. Por su importancia a la hora de encarar la comunicación en clave electoral hemos extendido nuestra investigación hasta el propio día de las elecciones tras el día de reflexión. Esto es, nuestras fechas de estudio comprenderán desde el 12 de abril hasta el 28 de abril de 2019. De esta forma, y gracias a los datos recabados con la herramienta Metricool, atisbaremos cuál es la estrategia de contenido seguida y en qué medida pudo influir en los usuarios en términos generales, sin desbrozar ni acotar los mismos, según criterios demográficos ni psicográficos. El periodo de control utilizado en nuestra investigación queda establecido en la misma duración del tramo inmediatamente anterior, lo que en nuestro caso, puesto que cubrimos un total de 17 días, será entre el 26 de marzo y el 11 de abril del 2019.

Las variables que son pertinentes para nuestra investigación, en relación con los perfiles de los partidos políticos analizados, quedan definidas en las diferentes imágenes, aunque ahora las relacionamos para una mayor claridad:

$\rightarrow 1$. Número de seguidores de cada partido político.

$\rightarrow 2$. Porcentaje de followers ganados por cada perfil.

$\rightarrow 3$. Número de tuits lanzados por cada partido.

$\rightarrow 4$. Porcentaje de tuits con respecto al periodo de control de cada partido.

$\rightarrow 5$. Número de retuits acumulados por cada perfil.

$\rightarrow 6$. Número de me gusta acumulados por cada partido político. 
$\rightarrow 7$. Porcentaje de retuits con respecto al periodo de control de cada perfil.

$\rightarrow$ 8. Porcentaje de me gusta con respecto al periodo de control de cada partido.

$\rightarrow$ 9. Publicación con más me gusta de cada perfil

$\rightarrow 10$. Publicación con más retuits de cada partido político.

La importancia de Twitter tanto en la comunicación política como en el periodismo es clave y en nuestros días ya no concebimos estos tres elementos sin una asociación explícita entre ellos. De hecho, Emily Bell, directora del Centro Tow para Periodismo Digital, expresa la importancia de esta red social comparándola con la invención de otro hito de la comunicación, como el teléfono. Afirma Bell (2016) que cualquier periodista debe manejar esta red social de forma eficaz para realizar de forma profesional su labor.

No hay que olvidar que en comunicación digital política estos tres factores mencionados anteriormente están sujetos al carácter matemático de las métricas, lo que implica el efecto del logaritmo. Como expresa MartínezRolán (2018: 151) «los cambios en el consumo de la información política no se deben a las maneras de escribir, sino a una lucha constante contra una compleja fórmula matemática».

Es, por tanto, Twitter una red que combina por un lado la producción de contenidos por parte de los usuarios, entre los cuales están los medios de comunicación y los partidos políticos, con la capacidad de recibir información por parte de los mismos actores. Esta combinación se triangula con la función de monitorización que todos los agentes hacen los unos con los otros. Es decir, las conexiones alcanzan un nivel de reciprocidad exponencial que generan millones de comentarios y de nuevas formas de producción de comunicación, sobrepasando claramente el concepto que la prensa tradicional poseía y las funciones que desarrollaba.

Estas características provocan que la crisis de la prensa tradicional se haya convertido en una oportunidad para reformular la misma y que, como afirma Hermida (2010), Twitter sea un punto de encuentro entre el periodismo y la Web 2.0. El usuario acude a esta red social para enterarse de forma instantánea de todo lo que está pasando y, como en nuestro estudio, para realizar el análisis minuto a minuto de las elecciones generales en España. 
Estamos, por tanto, ante un panorama social de gran impacto y con desarrollo en todo el territorio español que las redes sociales y el periodismo amplifican de manera meridiana. En este terreno nos quedamos con la reflexión de Congosto (2016: 123):

La participación de los usuarios en Twitter en temas sociales se manifiesta de una forma asimétrica, unos pocos despliegan mucha actividad mientras que el resto participa de una forma pasiva. Podría parecer en este escenario que la propagación está acaparada por unas élites de las que generalmente se asume que tienen más seguidores que seguidos. Sin embargo, se ha encontrado en todos los casos analizados un rasgo de meritocracia en el que usuarios con menos seguidores que seguidos han sido propagados. Induce a pensar que hay otros factores que influyen más en la propagación que la relevancia del autor en Twitter y que posiblemente uno de ellos sea la calidad del mensaje emitido. Es posible que la forma de consumir información en Twitter [...] propicie que los mensajes puedan ser leídos más allá de la red de seguidores, siendo probable que un mensaje ingenioso se difunda independientemente si se conoce o no al autor.

Para elaborar nuestra investigación debíamos enfrentarnos a un número creciente de aplicaciones que nos ayudaran y permitieran extraer los datos necesarios para llevar a cabo nuestro análisis. Tras realizar una selección de las que más se adecuaban a los parámetros que queríamos estudiar, decidimos escoger Metricool y Fanpage Karma como las herramientas que nos podían ayudar a seleccionar y acotar los resultados buscados entre los diferentes partidos políticos. Tras un periodo inicial de manejo de ambas, desechamos la segunda, no por su funcionalidad y manejo, que eran excelentes, sino por la explicitación de resultados, que resultaba mucho más clara en la primera. El establecimiento de correctos resultados que enfocaran de forma correcta el análisis cuantitativo, así como la necesaria curación de contenidos, que Early (2011) define mediante un proceso de negativización, es decir, por eliminación de la información que no sea provechosa, eliminando todo sesgo y cualquier circunstancia redundante, desfasado o trivial que no aporte valor a la misma.

\section{Resultados}

En este apartado realizaremos una descripción pormenorizada de los resultados alcanzados tras nuestra investigación en los perfiles en Twitter de los partidos políticos con alcance en todo el estado español. Comenzamos con el número 
total de followers que cada partido acumuló al final del periodo objeto de nuestro estudio.

Imagen 1. Total de followers.

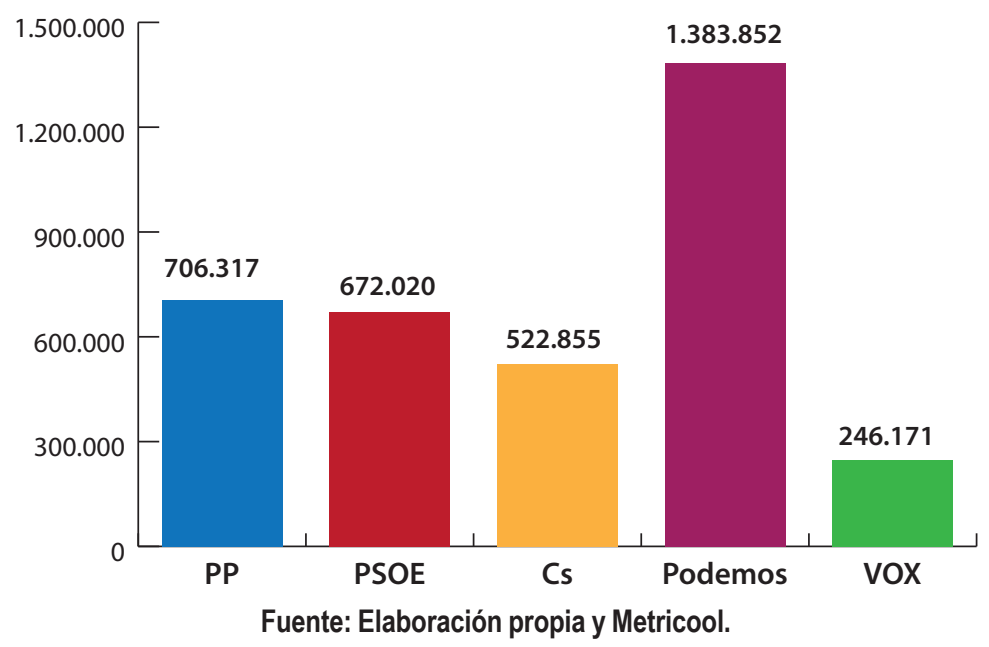

Como se puede observar, Twitter es la red social de Podemos. El partido liderado por Pablo Iglesias acumula más seguidores que los sumados por sus dos inmediatos perseguidores, Partido Popular y Partido Socialista Obrero Español, y quedan a mucha distancia los otros dos partidos que han surgido en los últimos años, Ciudadanos y Vox. Son casi un millón y medio de seguidores que están marcados por el ciberactivismo de la formación política de izquierdas, que usa esta red social para crear movilizaciones sociales que tiene su origen en el movimiento 15M, tal y como afirman Costa y Piñeiro (2011: 1463):

El 15-M o la spanish revolution, tal como fue bautizada por los medios extranjeros, supone ya un punto de referencia por lo que al empleo y potencialidad comunicativa de las redes sociales se refiere. Como parte de su estrategia en red, el empleo de Twitter como herramienta comunicativa instantánea para mensajes cortos así como la red Facebook para el comentario y la propuesta de iniciativas se han convertido en dos herramientas comunicativas básicas para el movimiento.

Los resultados cambian de manera radical si observamos el crecimiento de los seguidores durante el periodo temporal que es objeto de nuestro estudio. Son los datos que ofrecemos en el siguiente gráfico: 


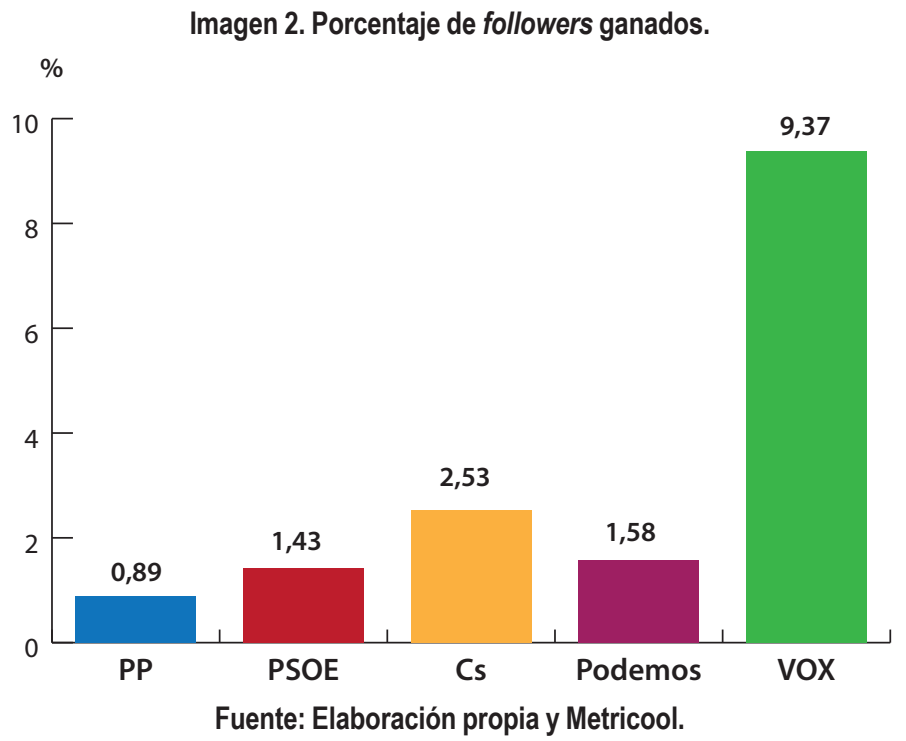

Dos datos llaman especialmente la atención en esta imagen. El primero es el sorprendente ascenso de Vox en Twitter, a pesar de que en términos absolutos es el partido que menos followers posee. Este incremento se justifica en que es el único partido de los cinco que están conformando nuestra investigación que es realmente novato en estas lides. Se trata de una formación sin representación parlamentaria hasta precisamente este evento y el interés de los distintos usuarios en la opción liderada por Santiago Abascal es creciente, tal y como refleja el gráfico.

Además, también se refleja una fuerte consolidación de los datos de los otros cuatro partidos en cuanto a esta red social puesto que ninguno de ellos alcanza un porcentaje de crecimiento del tres por ciento. Los usuarios de Twitter ya son maduros en cuanto a comunicación política y su monitorización de las distintas opciones políticas, sean afines o no, ya está establecida con anterioridad en su inmensa mayoría. En cuanto a la madurez de los seguidores de Vox es patente su crecimiento pero no es espectacular en su porcentaje, que ni siquiera alcanza el 10 por ciento en este periodo. Es cierto que son tan sólo diecisiete días de medición y que al resultar un tramo corto el porcentaje se revela como significativo, pero también es cierto que los usuarios cada vez reducen más sus ciclos de decisión en el entorno de la Web 2.0 y que por ello el seguidor de Vox de forma mayoritaria ya había decidido seguir a esta formación con anterioridad. Se trata, por tanto, de resultados paradójicos pero no contrarios, sino complementarios que nos ayudan a delimitar los efectos de esta red social para exponerlos con claridad. 
Pasamos ahora a analizar otra métrica de vital importancia en el análisis de redes sociales como es la producción de contenido. A la hora de acotarlo a Twitter, nos fijaremos en un análisis cuantitativo, en primer lugar, del número de tuits de cada partido en el periodo objeto de nuestro estudio:

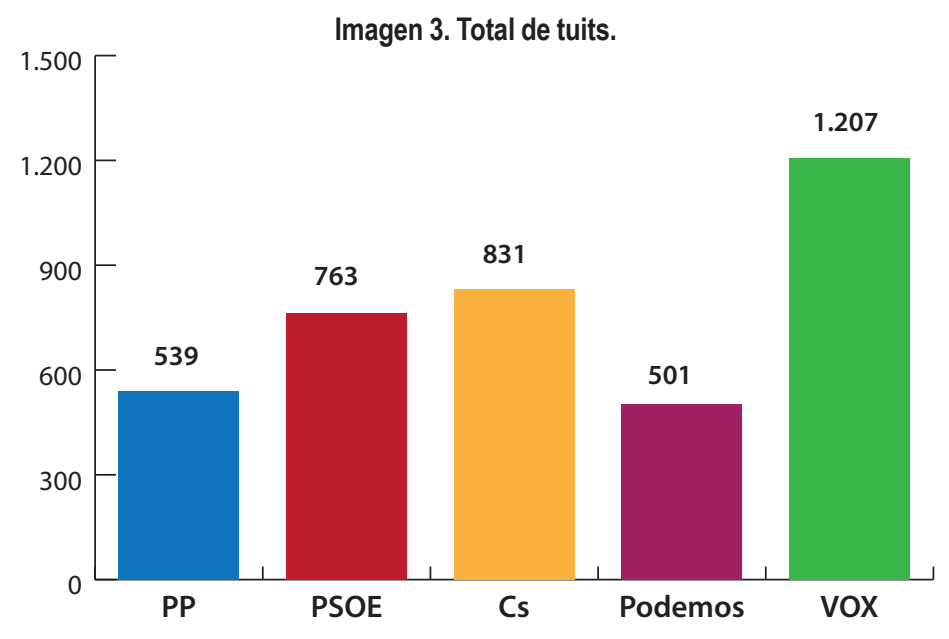

Fuente: Elaboración propia y Metricool.

La comparativa entre las distintas formaciones políticas pone en primera posición a Vox con más de mil tuits en los diecisiete días que abarca nuestra investigación. En este punto podemos establecer una primera correlación entre la producción de contenido desarrollada por la formación de derechas con el porcentaje de crecimiento de seguidores que acumuló en Twitter. Sin embargo, esta premisa queda cuestionada cuando observamos los resultados del perfil de Podemos en esta red social. Siendo el partido político que más seguidores acumula en términos absolutos, es el cuarto en porcentaje de crecimiento y es el último en cuanto a producción de contenidos. La actividad de Podemos es ciberactivista y selecciona muy bien todo aquello que quiere trasladar a sus seguidores, por lo que podemos afirmar que su consolidación le lleva a establecer una función clara de fidelización al contrario de lo que realizar Vox, cuya faceta de captación es prácticamente monopolística en nuestra investigación.

Todos nuestros apuntes dan un paso más si analizamos en términos porcentuales la producción de contenidos de los partidos políticos que estamos analizando en este periodo en Twitter: 


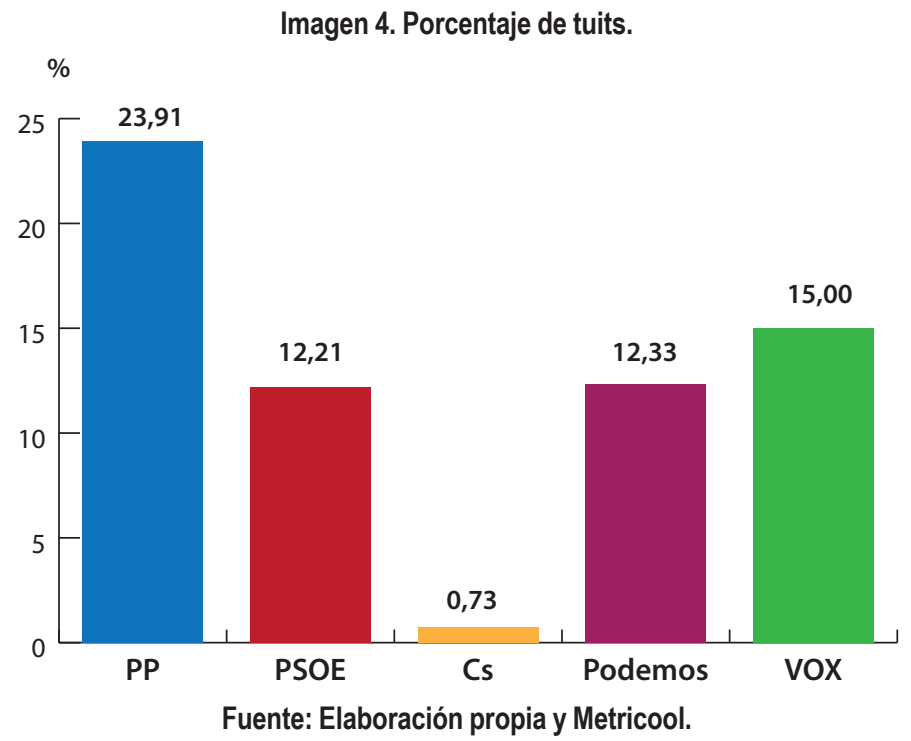

Si comparamos el tamaño de nuestra medición, diecisiete días, con un el mismo tramo justo en el tramo inmediatamente anterior, podemos observar como existe un claro aumento de la actividad de los partidos políticos en cuanto a la creación de contenidos en Twitter, a excepción de Ciudadanos. La formación liderada por Albert Rivera apenas aumenta en un uno por ciento el volumen de su producción, pero ocupa la segunda posición, justo por detrás de Vox, en cuanto a sus números en términos absolutos. De esta forma podemos resaltar la apuesta estratégica de la formación naranja por su comunicación en Twitter, dotándola por tanto de sostenibilidad y continuidad, sobre todo por encima de otros partidos ya establecidos en el sistema electoral, como el Partido Popular, el Partido Socialista Obrero Español y Podemos. No es el caso de Vox, puesto que, como ya hemos apuntado, realiza otra estrategia al enfrentarse a su primera cita electoral en toda España.

Con los datos obtenidos en el análisis de las redes sociales podemos pasar ahora a un examen muy interesante y clave en muchos proyectos como es el diagnóstico de las interacciones recibidas por parte de los partidos políticos en esta campaña y día de elecciones de abril de 2019 donde se configuraba tanto Congreso como Senado españoles. 
Gráfico 5. Total de interacciones.

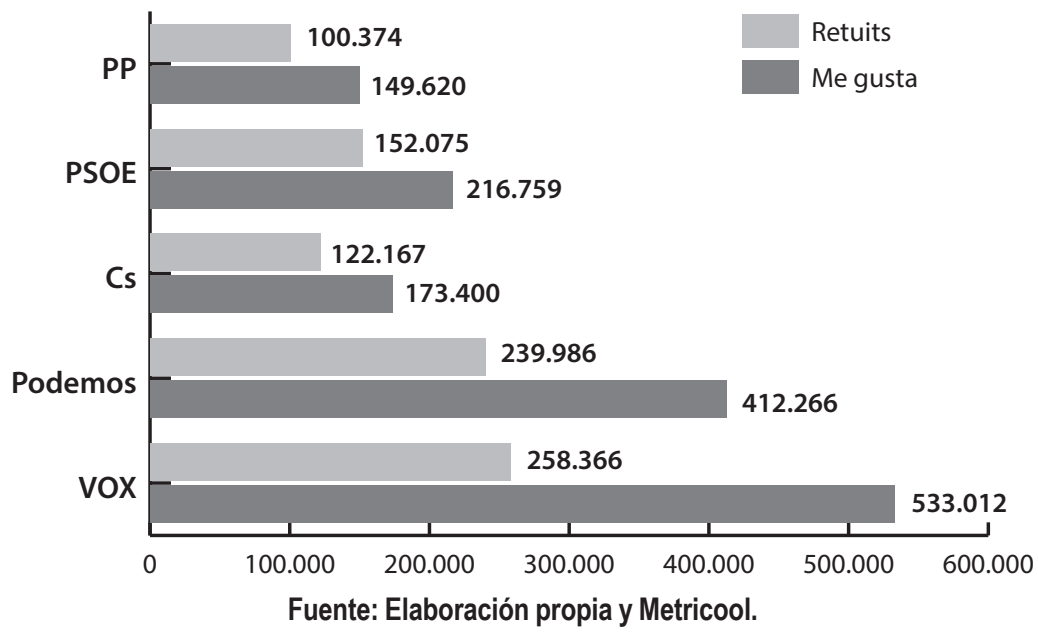

Resulta apabullante el dominio que ejerce Vox sobre esta métrica que en algunos casos se considera clave. Su triunfo cuantitativo es claro tanto en el número de 'Me Gusta' que reciben sus publicaciones como en el de retuits de las mismas. En este sentido también destacan, pero justo por lo contrario, el escaso volumen de interacciones que reciben los partidos que conforman el bipartidismo clásico. PP y PSOE quedan muy lejos de las dos opciones más extremas en ambas alas, Podemos y Vox, y sólo Ciudadanos se les une en un volumen de interacciones ciertamente escaso, sobre todo considerando que la opción centrista era la segunda en cuanto a producción de tuits. Si consideramos el esfuerzo del usuario en la interacción considerando éste como el tiempo que dedica en realizar la interacción, como considerar el retuit como, al menos, el doble de esfuerzo que el 'Me Gusta'. Desde esta premisa, y sumando los 'Me Gusta' al doble del valor de los retuits, las diferencias quedan todavía más claras puesto que nos remitimos a una cifra única y estable que permite establecer una clara jerarquía.

Vox ronda las ochocientos mil interacciones (791.380), quedando muy por encima de su inmediato perseguidor que es Podemos que sobrepasa las seiscientas cincuenta mil (652.224). A gran distancia se sitúa el PSOE (368.836), seguido de Ciudadanos que no llega a las trescientos mil (295.569); y por último el Partido Popular que roza el cuarto de millón (249.996).

Como hicimos con las métricas anteriores, también es clarificador para nuestra investigación el poder mostrar en términos de crecimiento porcentual cómo han funcionado las interacciones, comparados con el periodo muestra equidistante anterior. 
Gráfico 6. Porcentaje de interacciones.

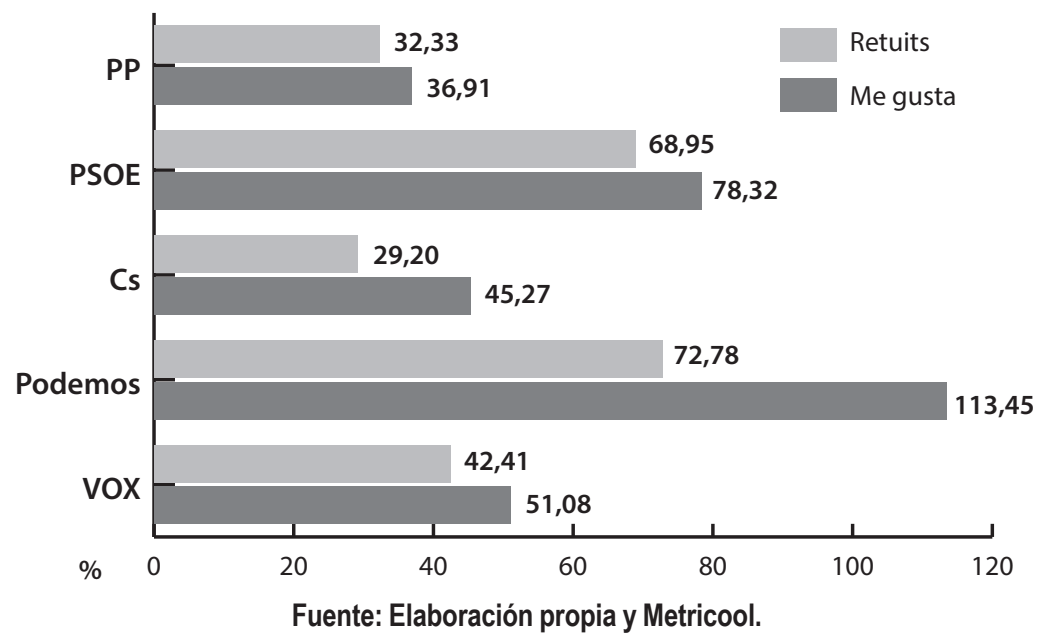

Es Podemos nuevamente el que vuelve a protagonizar otra métrica en este análisis en Twitter, demostrando que maneja esta red social con agilidad y con resultado eficaces. Las interacciones de los 'Me Gusta' de la formación morada pasan del doble y llegan hasta casi un 80 por ciento más en el caso de los retuits. La cibermovilización entre sus usuarios es patente $\mathrm{y}$, aunque no producen demasiada información, sí que tienen acólitos que secundan y mucho sus movimientos.

También es relevante la segunda posición del Partido Socialista Obrero Español, que había pasado prácticamente desapercibido en todos los estudios anteriores. El partido liderado por Pedro Sánchez también sabe movilizar a los suyos y les dirige mensajes que estimulan su interacción y en ambas variables, tanto 'Me Gusta' como retuits, están cerca de un aumento del 80 por ciento. En el caso del bloque de centro derecha, los resultados son muy parejos y destaca en este caso Vox por no lograr una mayor movilización de su electorado en esta red social, aunque el análisis cuantitativo debe establecer ahí su límite y dejar para otras herramientas cualitativas cuáles serían las posibles causas de estas circunstancias.Queda en nuestro análisis un último elemento que puede ayudarnos a entender de una manera más sencilla nuestro objeto de estudio. Buscamos una muestra mucho más reducida para establecer el parámetro de la interacción de una forma todavía más clara. Para ello buscamos el tuit con mayor número de interacciones de cada partido, tanto de 'Me Gusta' como de retuits, que sólo será coincidente en el caso de Ciudadanos. 
Gráfico 7. Publicaciones con más interacciones.

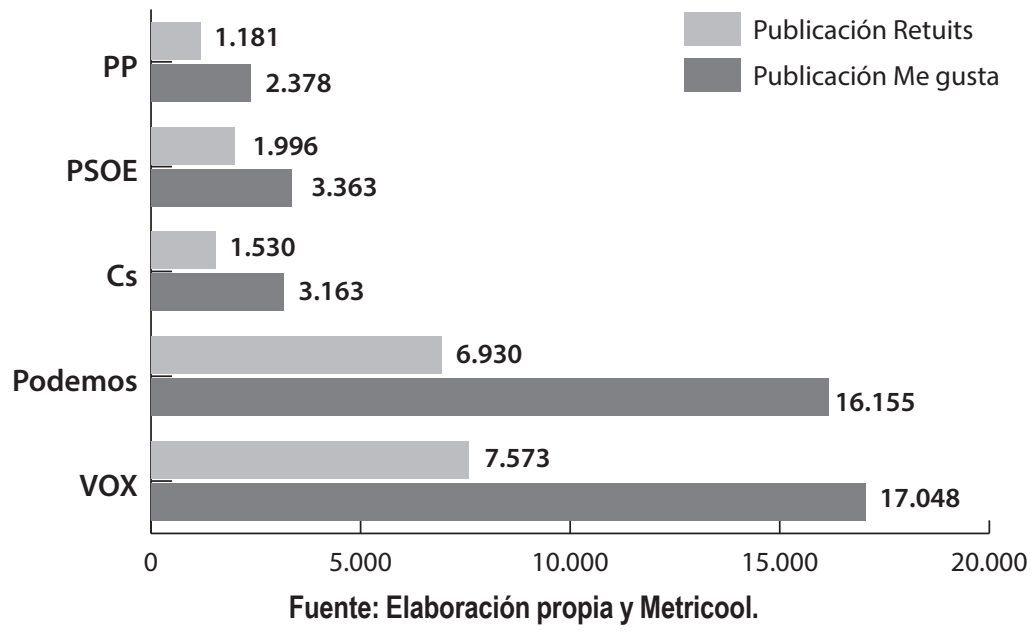

El gráfico vuelve a ser muy contundente con respecto la cibermovilización que realizan los partidos políticos más extremos en Twitter. Podemos y Vox superan de forma individual a los otros tres partidos que ni sumando sus interacciones llegaría a superarlos. Sus publicaciones son muy distantes en cuanto a contenido, pero no es objeto de nuestro análisis el adentrarnos en ese terreno sino mostrar lo que los datos nos evidencian y establecer nuestras conclusiones a partir de éstos. El Partido Popular es el principal damnificado de este análisis puesto que su tuit con mayor número de 'Me Gusta' y el que posee mayor número de retuits quedan muy por debajo del resto de competidores y queda claro que su movilización en Twitter no es para nada eficaz, si relacionamos este aspecto con el resto de los obtenidos en el apartado de interacciones.

\section{Conclusiones}

Comenzaremos nuestras conclusiones abordando lo que ha sido el objetivo general de nuestra investigación, es decir, cómo los partidos políticos han utilizado Twitter en el periodo comprendido entre el 12 y el 26 de abril de 2019, mientras se desarrollaba la campaña electoral y su ampliación hasta el día de las elecciones. Sin duda el uso general de Twitter ha favorecido a los dos partidos situados en los extremos del arco parlamentario, esto es, Vox y Podemos. Son los partidos que más veces se han situado en los primeros puestos de los distintos ítems que han confirmado nuestro estudio, destacando la movilización de sus seguidores.

El uso de Twitter cada vez es más complementario al consumo de la prensa tradicional, como demuestra el número estable de followers de todos los 
partidos políticos, a excepción de Vox, que ve incrementarse sus seguidores de manera notable. Unimos esta circunstancia a su contexto, que es el de que la formación de derechas era la primera vez que concurría a unas elecciones generales en España con posibilidades de obtener representación parlamentaria.

Igualmente la producción de contenidos en Twitter en la campaña electoral nos muestra cómo los partidos políticos se consideran una buena fuente de información para mostrar sin ambages su mensaje. El crecimiento es sobresaliente en casi todos los casos, destacando el Partido Popular, lo que no lleva aparejado un seguimiento correlativo por parte de sus seguidores, puesto que el análisis de las interacciones nos ha mostrado como la formación liderada por Pablo Casado era la última en este aspecto.

También resulta interesante observar cómo en el caso de Ciudadanos la producción de tuits es mucho más estable y apenas crece en el periodo electoral. La opción de centro no destaca en ninguna de las variables que hemos analizado pero muestra como el uso de Twitter puede desestacionalizarse, con pautas que ayudan a permanecer de forma sostenible en esta red social.

En cuanto a un objetivo más específico observamos como todos los partidos políticos han aumentado su número de seguidores, destacando el incremento de Vox, que ronda el 10 por ciento. Los diecisiete días analizados ofrecen un panorama maduro en cuanto a los seguidores de las distintas formaciones políticas, puesto que ninguna supera esa décima parte porcentual, a pesar del destacado periodo de análisis. La importancia de la cita electoral se verifica a través de este dato para todas y cada una de las opciones políticas.

Aunque en nuestro planteamiento inicial las interacciones ya eran una métrica lo suficientemente esclarecedora, decidimos apostar por otra que fuera cristalina, utilizando la ponderación del esfuerzo del usuario en las interacciones. Nuestro análisis nos lleva a establecer de forma meridiana que Vox y Podemos son los partidos ciberactivos que más cibermovilización producen. Sus resultados son sobresalientes en Twitter y dejan al bipartidismo tradicional, es decir PP y PSOE, muy claramente en la zaga de cualquiera de estos dos, ni siquiera uniendo sus fuerzas.

Por todo ello establecemos como conclusión final que Twitter se muestra como un medio de comunicación consolidado entre los partidos políticos que ayuda a la difusión de los mensajes, sin querer ser sustitutivo a la prensa tradicional sino complementario gracias a las características que le son propias dentro del entorno de la Web 2.0. Los partidos políticos encuentran en esta red social un lugar para la producción de mensajes, la interacción con los usuarios y la captación y/o fidelización de los mismos que en campaña electoral alcanza uno de sus puntos álgidos, independientemente de que los resultados en las urnas puedan ser distintos. 


\section{Bibliografía}

ABuín Vences, N. (2014). Las estrategias publicitarias de los anunciantes españoles en los Social Media. El caso de Facebook. Revista Internacional de Investigación en Comunicación aDResearch, 9(9), 64-75.

Alonso, M. A. y Adell, A. (2011). Marketing Político 2.0. Barcelona: Grupo Planeta.

Bell, E. (2016) My Innovation. Columbia Journalism Review, 54(5), 28.

Bell, E. y Owen, T. (2017). The Platform Press: How Silicon Valley Reengineered Journalism. Tow Center for Digital Journalism. Columbia Journalism School.

Cabezuelo, F. y GonzÁlez, A. (2014) El Twitter de Aristóteles. Una revisión de los conceptos clásicos de la retórica clásica en la actual sociedad digital. Vivat Academia, 126, 20-30.

Cabezuelo-Lorenzo, F.; Rey-García, P. y Tapia-Frade, A. (2016). Análisis de las herramientas de control ciudadano sobre los representantes públicos: $\mathrm{La}$ transparencia informativa municipal en Castilla y León. Revista Latina de Comunicación Social, 71, 1261-1279. Recuperado desde: http://www.revistalatihacs.org/071/paper/1145/65es.html

Galdevilla Domínguez, D. (2009). Democracia 2.0: La política se introduce en las redes sociales. Pensar la Publicidad, 3(2), 31-48.

Campos-Domínguez, E. (2017). Twitter y la comunicación política. El profesional de la información, 26(5), 785-793. Doi: https://doi.org/10.3145/epi.2017.sep.01

CASERo-Ripollés, A. (2018). Research on political information and social media: Key points and challenges for the future. El profesional de la información, 27(5), 964-974. Doi: https://doi.org/10.3145/epi.2018.sep.01965.

Costa-SÁnchez, C. y Piñeiro-Otero, T. (2011). Activismo social en la web 2.0. El movimiento 15M. Vivat Academia, 117E, 1458-1467.

Chaves-Montero, A. (2017). Comunicación Política y Redes Sociales. Sevilla: Ediciones Egregius.

Congosto, M. (2016). Caracterización de usuarios y propagación de mensajes en Twitter en el entorno de los temas sociales. Tesis doctoral Universidad Carlos III de Madrid. Departamento de Ingeniería telemática.

DADER, J. L. y CAMPOS, E. (2016). Internet parlamentario en España (1999-2005): Los recursos para el contacto ciudadano y su uso, con una comparación europea. Zer, 20, 105-132.

EarLy, S. (2011). Content Curation: Contributing to Improved 'Findability'. Information Outlook, 15(8), 14-16.

GUTIÉRREz-RuBí, A. (2011). La politica vigilada. La comunicación política en la era de Wikileaks. Barcelona: Editorial UOC. 
Hermida, A. (2010). From TV to Twitter: How Ambient News Became Ambient Journalism. Media-Culture Journal, 13.

López ABelLÁN, M. (2012). Twitter como instrumento de comunicación política en campaña: Elecciones Generales 2011. Cuadernos de Gestión de Información, 69, 84.

Marketing Directo (2016). Twitter: la mayor plataforma de influencia politica según los votantes españoles. Recuperado el 29 de junio de 2019 desde: https://www.marketingdirecto.com/digital-general/social-media-marketing/twitter-mayor-plataformainfluencia-politica-segun-votantes-espanoles.

Martínez Rodrigo, E. (2016). La utilidad de Twitter en el aprendizaje de la titulación periodística en María Elena del Valle (Coord). Primer encuentro de expertos en tecnología. UGTA Unimet.

Martínez Rolan, X. (2018). La actividad de los partidos políticos españoles en Facebook 2014-2018. La tiranía del algoritmo. Revista de Comunicación de la SEECI, 47, 143-155.

Matud, Á. (2009). Política 2.0. Algo más que Internet. Nueva Revista, 121, 46-59.

Orituela, J. L. (2011). Mundo Twitter. Madrid: Alienta.

Pérez-Tornero, J. (2015). El futuro de la sociedad digital y los nuevos valores de la educación en medios. Comunicar, 25, 247-258.

Rodríguez FernÁNDEZ, Ó. (2011). Twitter: aplicaciones profesionales y de empresa. Madrid: Anaya.

Santiago, R. y Navaridas, F. (2012). La web 2.0 en escena. Web 2.0 comes on the scene. Píxel-Bit. Revista de Medios y Educación, 41, 19-30.

Sotelo González, J. (2012). Deporte y social media: el caso de la Primera División del fútbol español. Historia y Comunicación Social, 17, 217-230. Recuperado desde: $h$ ttp://dx.doi.org/10.5209/rev_HICS.2012.v17.40607

SHogan, C. J. (2010). Blackberries, tweets, and YouTube: Technology and the future of communicating with Congress. PS: Political science \& politics, 43(2), 231-233.

TúÑEz-López, M.; García, J. S. y Guevara-Castillo, M.(2011). Redes sociales y marketing viral: repercusión e incidencia en la construcción de la agenda mediática. Palabra Clave, 14(1), 53.

Para citar este artículo: Serrano-Oceja, F.; Gonzálvez-Valles, J. E. y Viñarás-Abad, M. (2019). La gestión de las redes sociales en la comunicación política y su influencia en la prensa. index.comunicación, 9(1), 173-195. 
